\title{
Risk of Colorectal Cancer in Inflammatory Bowel Disease: Prevention and Monitoring Strategies According To Risk Factors
}

\begin{abstract}
In this narrative review, we report on colorectal cancer risk factors and prevention and monitoring strategies. Colorectal cancer (CRC) is slightly increased in inflammatory bowel disease (IBD) patients, with roughly a 2.5-fold increase compared to the general population. Clinical features associated to CRC risks are extent and severity of colonic involvement, disease duration, concomitant primary sclerosing cholangitis (PSC) and/or familial history of CRC in first-degree relatives. Colonic Crohn's disease (CD) and ulcerative colitis (UC) share similar risks when similar colonic extent is affected. Risk stratification affects outcomes and surveillance programs. Nerwer endoscopic techniques substantially ameliorated diagnostic performance of endoscopy, and nowadays the standard for CRC surveillance in IBD patients is high-definition endoscopy, with dye-spray or virtual colonoscopy, oriented at targeted (+ random) colonic biopsies.

Visible dysplastic lesions should be considered for endoscopic resection, while invisible dysplasia is still a mandatory proctocolectomy indication.

Nerwer endoscopic interventional techniques (endoscopic mucosa resection-EMR, and endoscopic submucosal dissection - ESD) are appropriate therapeutic techniques to be delivered, but longterm risks of cancer should be balanced towards proctocolectomy.
\end{abstract}

Keywords: Inflammatory Bowel Disease; Cancer; Surveillance; Endoscopic Techniques CMI 2021; 15(1): 1-13

bttp://dx.doi.org/10.7175/cmi.v15i1.1464

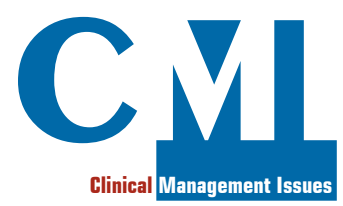

Clinical Management
Gastroenterology Unit,

Mauriziano Hospital,

Torino, Italy

2 Gastroenterology

Department, Palermo

University, Palermo, Italy

\section{BACKGROUND—THE LANDSCAPE OF COLORECTAL CANCER ISSUE IN INFLAMMATORY BOWEL DISEASE}

In this narrative review, we report on colorectal cancer risk factors and endoscopic management.

\section{Risk of colorectal cancer and relevant risk factors}

Patients with long-standing Inflammatory Bowel Disease (IBD) are at increased risk of developing colorectal cancer (CRC). People with Ulcerative Colitis (UC) and Crohn's Disease (CD) experience a 2-to-2.5-fold higher risk of colorectal cancer compared with general population [1-3]. The risk of death associated with this malignancy is around 1.5 times greater in people suffering from IBD than in the general population [4].

However, recent population-based studies showed a trend to decreasing risks of CRC in IBD patients, probably due to improved medical therapy and CRC surveillance, so that now the risks seem not to exceed those of the general population: relative risk (RR) vs. general population being 0.57 (95\% CI: $0.41-0.80)$ in UC patients and 0.77 (95\% CI: 0.43-1.39) in CD patients, respectively [5]. Data from the Literature would suggest that the risks of developing colorectal cancer for CD and UC patients with the similar extent of colonic involvement are similar [6].
Corresponding author Marco Daperno Gastroenterology Unit, Mauriziano Hospital, Largo Turati 62, 10128 Torino, Italy mdaperno@gmail.com Fax +3901150182536 Tel: + 390115082534

Received: 16 March 2020 Accepted: 26 October 2020 Published: 5 February 2021 


\begin{tabular}{|c|c|}
\hline $\begin{array}{l}\text { High CRC risk } \\
\text { factors }\end{array}$ & $\begin{array}{l}\text { - Extensive colonic involvement (pancolitis or CD with } \\
>50 \% \text { colonic involvement) } \\
\text { - Moderate-to-severe endoscopic or histological active } \\
\text { inflammation sustained over time } \\
\text { - Primary Sclerosing Cholangitis } \\
\text { - Onset disease }<15 \text { years } \\
\text { - Family history of sporadic CRC in a first-degree relative } \\
<50 \text { years } \\
\text { - Presence of a stricture or dysplasia detected during the } \\
\text { previous } 5 \text { years }\end{array}$ \\
\hline $\begin{array}{l}\text { Intermediate } \\
\text { CRC risk factors }\end{array}$ & $\begin{array}{l}\text { - Mild or moderate endoscopic or histological inflammation } \\
\text { sustained over time } \\
\text { - Family history of sporadic CRC in a first-degree relative } \\
>50 \text { years } \\
\text { - Presence of inflammatory polyps }\end{array}$ \\
\hline RC & $\begin{array}{l}\text { - Pancolitis without inflammation } \\
\text { - Left-sided UC or CD with <50\% colonic involvement }\end{array}$ \\
\hline
\end{tabular}

Table I. Risk stratification for colorectal cancer is based on several clinical factors

$\mathrm{CD}=$ Crohn's Disease; $\mathrm{CRC}=$ Colorectal Cancer $\mathrm{UC}=$ Ulcerative Colitis
The risks of CRC begin to significantly increase approximately 7 years after diagnosis, and they progress linearly thereafter. Disease duration is an important risk factor: according to a meta-analysis of 116 studies, the probability of developing CRC in patients with UC was $1.6 \%$ at 10 years, $8.3 \%$ at 20 years, and $18.4 \%$ at 30 years after UC diagnosis [7]. This increased incidence of UC-associated CRC was thought to be 4-to-10 times greater than that for sporadic $\mathrm{CRC}$, and the average age of onset to be 20 years earlier [7]. Based on these data, the first screening colonoscopy is generally recommended 8-10 years after disease onset $[8,9]$. Other clinical features increasing $\mathrm{CRC}$ risk include young age at diagnosis, extensive colonic involvement and severity of intestinal inflammation: the overall risk of CRC among patients with extensive UC is increased by almost 5 -folds $(\mathrm{RR}=4.8$; 95\% CI: 3.9-5.9) [5]. A recent populationbased cohort study showed that $\mathrm{CD}$ patients have an increased risk of CRC diagnosis and $\mathrm{CRC}$ mortality compared with general population (respectively $\mathrm{HR}=1.40$ and $\mathrm{HR}=1.42$ ). Moreover, CRC is not diagnosed earlier in $\mathrm{CD}$ patients as compared to general CRC population, and $\mathrm{CD}$ patients with disease duration $\geq 8$ years or PSC diagnosis displayed an increased risk of CRC diagnosis and mortality if $\mathrm{CD}$ onset was before 40 years [3].

Independently, there are other clinical features associated to CRC risks in IBD.

Family history of sporadic CRC increases the risk of CRC in IBD patients by approximately 2.5 folds (1.4-4.4) if first-degree relative with sporadic $\mathrm{CRC}$ was $>50$-year- old at the time of CRC diagnosis and by 9.2 folds (3.7-23.0) if first-degree relative with sporadic CRC was $<50$ year [10].

Primary sclerosing cholangitis (PSC) is associated with an increased risk of $\mathrm{CRC}$ and dysplasia with an odds ratio of 3.2 when compared to patient with IBD without PSC [11].

Chronic inflammation plays a key role in development of dysplasia and CRC in IBD. Colorectal cancer develops through a multistep process, where low- and high-grade dysplasia represent and intermediary stage that process to cancer through a sequence inflammation-dysplasia-cancer. There are two types of dysplasia, according with different microscopic features: low-grade and high-grade dysplasia. The term "indefinite for dysplasia" is used when it cannot define whether a lesion is non-neoplastic or neoplastic, which may happen when there is microscopic inflammation associated to IBD mimicking true dysplasia [12].

\section{Risk stratification of IBD patients and consequent surveillance intervals}

Based on risk stratification (Table I) and acknowledging the fact that dysplasia risks should be negligible for proctitis only and before 7-8 years from disease diagnosis, present CRC surveillance algorithm prescribe [9]:

- a first screening colonoscopy for all patients around 7-8 years after diagnosis (in order to confirm maximal microscopic disease extent, disease endoscopic and histologic activity, and to exclude early dysplasia);

- then, based on risk factors following surveillance, colonoscopy should be planned yearly in case of high-risk patient, every 3 years in case of intermediate risk, and every 5 years if low risk is the case.

Only patients co-affected by PSC should undergo yearly surveillance colonoscopy after diagnosis, due to their very elevated personal risk of CRC.

\section{STATE OF THE ART-HOW TO DIAGNOSE COLORECTAL CANCER IN IBD PATIENTS AND WHEN SHOULD THEY UNDERGO SURVEILLANCE}

Screening and surveillance for CRC in IBD are mandatory in order to improve 
CRC-related survival in IBD patients. International gastrointestinal societies recommended endoscopic surveillance with colonoscopy to identify and eradicate colonic lesions at an early non-invasive stage to reducing colorectal cancer incidence and mortality $[1,9,13,14]$.

Several endoscopic techniques for dysplasia surveillance have been evaluated for IBD, including standard-definition and highdefinition white-light endoscopy, chromoendoscopy, narrow-band imaging (Olympus, Tokyo, Japan), i-SCAN (Pentax, Tokyo, Japan) autofluorescence (Olympus, Tokyo, Japan), Fujinon Intelligent Colour Enhancement (FICE) and full-spectrum endoscopy (Fujifil Corporation, Tokyo, Japan).

According to international guidelines, chromoendoscopy with target biopsy is indicated as top-quality approach for dysplasia surveillance in IBD patients $[8,9$, $13,14]$. White-light endoscopy with random biopsies is considered appropriate if chromoendoscopy is not available [9-11], while other endoscopic techniques are not recommended.

\section{Standard-definition and high-definition white-light endoscopy}

The standard method in CRC surveillance was, until recently, Standard Definition White Light Endoscopy (SD-WLE), with the use of targeted as well as random quadrant biopsies every $10 \mathrm{~cm}[8,15]$. With the advent of the High-Definition-White Light Endoscopy (HD-WLE), the endoscopist can better identify dysplastic lesion. High-definition (HDTV or 1080p system) endoscopic platforms deliver image signals with higher pixel density if compared to standard definition (EDTV or 480p system) platforms, and when projected on high-definition monitors it leads to sharper images with fewer artifacts [14]. A high-definition system includes a high-definition endoscope, processor, cabling, and monitor. In a retrospective observational study, it was showed that dysplasia was discovered in approximately twice as many patients undergoing high-definition colonoscopy ( $\mathrm{n}=203)$, as compared to a cohort undergoing standarddefinition colonoscopy ( $n=154)$ : the observed adjusted prevalence ratio was $2.2(95 \%$ CI: 1.1-4.5) [16]. The SCENIC consensus statement strongly recommended the use of HD-WLE over SD-WLE, given that most dysplastic lesions are visible, the improved visualization and lack of negative effects [14].

\section{Random biopsies}

Surveillance with random biopsies consists of four quadrant biopsies every $10 \mathrm{~cm}$ throughout the colon. Dysplasia in IBD was previously thought to be flat and difficult to visualize and to detect, thus the historic recommended screening modality was WLE with random four quadrant biopsies every $10 \mathrm{~cm}$ (24). Random biopsy only samples less than $1 \%$ of the luminal mucosa; has a subpar detection rate (<2 per 1000 biopsies taken) and when used in conjunction with advanced endoscopic techniques, it does not affect clinical decisions [17].

The biopsy forceps surface has $0.2 \mathrm{~cm}^{2}$ and the colorectal surface is about $2700 \mathrm{~cm}^{2}, 40$ random biopsies would sample only $0.03 \%$ of the colic surface. Therefore, to have a sample from dysplastic areas $\geq 2 \mathrm{~cm}^{2} 1350$ biopsies would be necessary to sample it with adequate probability [18].

Current guidelines suggest that random biopsies can be acquired during HD colonoscopy if dye spray chromoendoscopy is not available or technically feasible $[9,14]$. Random biopsies remain a reasonable alternative if there are condition that lower the diagnostic yield, such as inflammation, pseudo-polyps, poor preparation or a poorly visualized mucosa [19] or in special circumstances such as a personal history of dysplasia, concomitant PSC, or a foreshortened colon.

\section{Dye-Spray Chromoendoscopy}

Dye-Spray Chromoendoscopy (DCE) involves the topical application of dye on the colonic surface during colonoscopy, thereby providing contrast enhancement to improve surface contrast and visualization of epithelial surface detail and augment dysplasia detection. Methylene blue and indigo carmine are the most used agents and they are delivered to the colonic mucosa via a spray-catheter or through the colonoscope biopsy channel. Areas that are macroscopically elevated or depressed, friable, obscure in vasculature, and with villous or nodular pattern can be detected more easily and therefore targeted biopsies can be taken [20]. When performing DCE, it is important to avoid active disease and to have adequate bowel preparation. DCE may reduce the need for random biopsies and may allow prolonged surveillance-interval, leading to cost reduction, as well as increase in the detection sensitivity of dysplastic lesions per examination [20]. 
A meta-analysis studied the overall difference in the detection of dysplasia between chromoendoscopy and white light endoscopy: it was $7 \%$ (95\% CI: 3.2-11.3) on a per patient analysis with a number needed to treat (NNT) of 14.3. The difference in the proportion of lesions detected by targeted biopsies was 44\% (95\% CI: 28.6-59.1) and flat lesions was $27 \%$ (95\% CI: $11.2-41.9)$ in favor of chromoendoscopy [21].

DCE was superior to WLE: a DCE examination without any findings was considered as the most probable indicator for a patient without any level of dysplasia, whereas an exam with any sort of findings at DCE was positively correlated with earlier referral for colectomy $(\mathrm{HR}=12.1 ; 95 \%$ CI: 3.2-46.2) [22].

Despite the SCENIC consensus recommends DCE over WLE when using SD colonoscopy and suggests the use of $\mathrm{DCE}$ over WLE also when using HD colonoscopy, new evidence is conflicting as to the benefit of DCE over WLE with newer scopes $[16,19]$. In a recent systematic review and network metanalysis, full spectrum highdefinition white-light endoscopy seems to be the first-line approach for dysplasia surveillance in IBD [23]. Other techniques such as chromoendoscopy, narrow-band imaging, autofluorescence, Fujinon intelligent color enhancement (FICE), and full spectrum high-definition white-light endoscopy may be comparable.SD-WLE probably had lower odds of detecting neoplastic lesion by target biopsy and shorter procedural time compared to chromoendoscopy [23].

An economic analysis concluded that DCE with targeted biopsies was less costly and more effective than white-light colonoscopy with random biopsies, suggesting that chromoendoscopy should be used in place of white-light endoscopy when surveillance colonoscopy is performed. The cost-effectiveness of chromoendoscopy increased with increasing surveillance interval, suggesting that varying the surveillance interval based on CRC risks and on DCE evaluation may be appropriate and could increase cost-effectiveness of surveillance [24].

\section{Virtual chromoendoscopy}

Technological advancement led to newer modalities, even when based on older technologies, for mucosal assessment. The newest endoscopic devices carry digital filters and electronic algorithms mimicking chemical chromoendoscopy (by filtering specific light wavelengths to better outlight mucosal abnormalities, overcoming the issues of classical DCE). Dye-less or virtual chromoendoscopy has been developed by three major manufacturers on their proprietary endoscopic platforms. Narrow-banding-image (NBI, Olympus) filters out red and green light bands while restricting to blue light bands closer to the $415 \mathrm{~nm}$ wavelength. This modality allows for visualization of the vasculature of the most superficial layers of the mucosa, and it enhances different patterns correlating to different degrees of mucosal inflammation. NBI colonoscopy may be of value in best determining the grade of inflammation in patients with quiescent UC [25].

The i-Scan system (Pentax) is a digital enrichment system of endoscopic imaging, which can provide different types of images based on vessel (i-Scan v), mucosal pattern (i-Scan p), or surface architecture (i-Scan $\mathrm{SE})$. Each of these algorithms can be selected by pressing a preassigned button on the scope, being readily available during endoscopy [20]. I-Scan may be a promising technique to assess inflammation and distinguish neoplastic from non-neoplastic lesion in the colon. The vascular and mucosal pattern may be used to characterize inflammation even when there are no ulcers or friability [26].

For virtual chromoendoscopy techniques, no superiority, but at best only non-inferiority was shown when comparing to HDDCE $[26,27]$.

\section{Confocal laser endomicroscopy}

Confocal laser endomicroscopy (CLE) is a cutting-edge new imaging technique for dysplasia detection, which allows in vivo microscopic inspection. This new imaging modality is used with HD-WLE and DCE to further define suspicious lesions and to predict their histology, with real time analysis of cellular and subcellular features at very high resolution. The technique requires fluorescent dyes, using fluorescein intravenously or topically. The result is the generation of high-quality images, comparable to traditional histology [20].

\section{STATE OF THE ART-HOW TO TREAT COLONIC DYSPLASIA AND CANCER}

Based on endoscopic appearance, there are two different scenarios regarding dysplasia [22]: 
1. dysplastic lesion endoscopically visible, like polyps, confirmed with targeted biopsies or after their endoscopic resection;

2. endoscopically invisible dysplasia, detected at random biopsies in areas of endoscopically normal mucosa. This latter form of dysplasia harbors an increased $\mathrm{CRC}$ risk.

\section{Endoscopically visible dysplasia}

Visible dysplastic lesions, when found in colonic areas unaffected by active colitis, should be removed with standard polypectomy techniques [22]. For polypoid and non-polypoid visible lesions with evident margins, endoscopic resection is recommended whenever complete and en bloc resection is possible [28]. Features of underlying malignancy include ulcerated lesions, inability to lift the lesion after submucosal injection with saline solution, and surrounding neoplastic changes; all these features are associated with failures in complete resections [29]. Whenever visible dysplastic lesions cannot be resected endoscopically, proctocolectomy should be recommended [8].

Endoscopic mucosal resection (EMR) or endoscopic submucosal dissection (ESD) should be considered appropriate techniques to resect colorectal lesions in IBD patients, even if only small-size studies with these techniques reported high success rates [30-32].

After dysplastic polypoid lesions have been completely resected, an appropriate endoscopic surveillance program must be adopted. The ideal timing of subsequent procedures is still debated [33]. Following EMR or ESD resection, the Global Interventional IBD Group recommends a follow-up surveillance colonoscopy with $\mathrm{CE}$ and biopsies at the resection site as early as three months after index resection [28].

In order to minimize risks not to detect the resection area at later timepoints, whenever a large polyp is removed, a mucosal tattoo should be carried out (in order to focus at best subsequent surveillance colonoscopies and biopsies). Current guidelines recommend also to obtain additional biopsies of the mucosa surrounding the visible dysplastic lesion site, in order to exclude adjacent dysplasia [8, 19]; even if reasonable, this approach was not shown to increase the diagnostic yield for dysplasia.

\section{Endoscopically invisible dysplasia}

This second setting is associated up to $22 \%$ with invisible low-grade dysplasia (LGD) and 45-67\% with invisible highgrade dysplasia (HGD) with a high rate of synchronous CRC [34]. Any endoscopically invisible dysplasia discovered at the time of random biopsies should be confirmed with a pathologist experienced in IBD [35]. Recent guidelines also recommend that samples belonging to patients with reported invisible dysplasia, should be referred to an experienced endoscopist for a repeated HD colonoscopy with DCE and repeat random biopsies $[14,19]$. According to a recent paper, LGD, after a median follow-up of 36 months, progressed to HGD or CRC only in $5 \%$ of patients [36]. Therefore, if LGD or no dysplasia is present, the risks and benefits of continued surveillance or proctocolectomy can be discussed. In cases of endoscopically invisible HGD or multifocal LGD, total proctocolectomy indication is mandatory $[14,19]$.

\section{SPECIAL SITUATIONS}

\section{lleal pouch anal anastomosis (IPAA)}

Restorative proctocolectomy with IPAA reduced the risk of developing CRC. However, malignant degeneration of the pouch may still arise. For UC patients undergone restorative proctocolectomy with IPAA, development of dysplasia in the anorectal or ileal pouch mucosa is rare. A history of dysplasia or CRC may increase the risks of pouch neoplasia significantly. In a study on 1200 patients with UC and IPAA over 20 years, only $<2 \%$ of patients developed pouch neoplasia and $1.3 \%$ developed adenocarcinoma [37].

Risk factors for dysplasia following IPAA include a history of dysplasia or CRC, history of PSC, refractory pouchitis, and severally inflammed atrophic pouch mucosa [37]. Patients with risk factors should be considered for annual surveillance included biopsies in the pouch and within the anal transition zone [38].

In patients with IPAA without cancer risk a surveillance is proposed every 3 years, although the optimal interval is still unknown and also depends on colectomy indication for cancer of for refractoriness [38]. 


\section{Primary sclerosing cholangitis (PSC)}

Most patients with PSC have IBD, with an estimated prevalence of IBD in patients with PSC ranging from $50 \%$ to $80 \%$. In the majority of cases, Ulcerative Colitis is the intestinal disease. Patients with PSC and IBD display higher CRC risks if compared to patients with PSC or IBD alone. Patients with concurrent PSC and UC display a 4-fold increased risk of CRC if compared with patients affected by UC alone [29].

Intestinal disease in PSC-IBD is typically more likely to be quiescent, thus both activity and dysplasia in these patients can only be found after active screening with colonoscopy and multiple biopsies [39]. Furthermore, the progression of colonic neoplasm from low-grade dysplasia to advanced colorectal neoplasia is more frequent in patients with PSC-IBD (regardless of severity of PSC) as compared to patients affected by IBD alone [40].

Unlike classical IBD, CRC risks (which brings increased CRC risks only after IBD lasts a decade or more), patients with PSCUC where shown to be at increased risks of $\mathrm{CRC}$ as soon as diagnosis of either of the two diseases is done [40].

Moreover, CRC risks are still present after liver transplantation is carried out, thus routine surveillance for CRC is essential [41] as early as PSC is diagnosed, but also yearly all life-long thereafter.

\section{Perianal disease}

In a recent analysis of data from the CESAME cohort in France, patients with anal and/or perianal Crohn's disease were shown to carry an increased risk of anal cancer, including perianal fistula-related cancer, as well as a remarkable risk of rectal cancer [42].

This excess incidence may be attributed to a conjunction of possible HPV infection and chronic local inflammation. In patients with anal and/or perianal Crohn's disease, the risk of anorectal cancer was 11 times greater than the risk of colon cancer [42].

In this setting, surveillance programs should be considered, focused at detecting premalignant dysplastic lesions and early anorectal cancers in patients with longstanding anal and/or perianal CD. However, the timing and modalities of surveillance are extremely variable [43].

\section{Small bowel cancer}

Small bowel neoplasia can develop in patients with $\mathrm{CD}$ involving the small bowel.

In a meta-analysis [44], the pooled incidence of $\mathrm{CD}$-associated small bowel carcinoma was $0.3 / 1000$ patients (95\% CI: $0.1 / 1000-0.5 / 1000)$, the corresponding prevalence was $0.16 \%$ (95\% CI: $0.12-$ 0.21 ); compared to the incidence in an age-matched standard population, the risk of small bowel cancer was increased by factor 18.75 .

In a nationwide cohort study, the incidence rates of small bowel adenocarcinoma (SBA) were 0.235 per 1000 patient-years (95\% CI: 0.076-0.547) among patients with small bowel CD and 0.464 per 1000 patientyears (95\% CI: 0.127-1.190) among those with small bowel CD for $>8$ years. This accounted for approximately $30 \%$ of the risk of colorectal cancer in patients with $\mathrm{CD}$ of the colon. Patients with small bowel CD and small bowel CD for 0.8 years had an SBA standardized incidence ratio of 34.9 (95\% CI: $11.3-81.5)$ and 46.0 (95\% CI: 12.5-117.8), respectively [45].

In a recent multicenter case-control study, incidence of SBA was studied. SBA occurred $12.1 \%$ patients and was significantly more frequent in $\mathrm{CD}$ when compared with UC (CD vs. UC $p=0.0001$ ). All cases of SBA in $\mathrm{CD}$ occurred in fibro-stricturing small bowel lesions. SBA also occurred in the ileal pouch of $1 \mathrm{UC}$ patient [46].

Small bowel adenocarcinoma associated with $\mathrm{CD}$ as a whole showed poor prognosis (5-year overall survival rate: $26-38 \%$ ), and this is partly due to the advanced stage at diagnosis and to their often incidental finding at surgical resection for bowel stricture [47].

Despite different risk factors involved in the development of small-bowel cancer in $\mathrm{CD}$ patient are generally considered (i.e., distal jejunal/ileal CD site, strictures and chronic penetrating disease, long disease duration, young age at diagnosis, male sex, use of steroids and immunomodulators, small-bowel bypass loops, strictureplasties, and environmental factors) [48], some studies didn't confirm some of these associations. Therefore, according to European guidelines, long-standing $\mathrm{CD}$ and stricturing disease seem to be the factors most strongly associated with elevated risk of small-bowel cancer. Small bowel neoplasia should be suspected and investigated in patients with $\mathrm{CD}$ who develop symptomatic strictures after a prolonged symptom-free period or stric- 
tures that are refractory to medical therapy, but there is not enough strong evidence to make clear recommendations on primary prevention of small-bowel neoplasia in CD patients [41].

Early diagnosis of small bowel adenocarcinoma in long-standing Crohn's disease is a challenge. Different advanced imaging and endoscopic techniques (e.g., capsule endoscopy, device-assisted endoscopy, magnetic resonance imaging-MRI, computed tomography-CT) may allow diagnosis of small bowel involvement in Crohn's disease and earlier cancer. At present, even if they are costly and complex to be used for routine surveillance of all CD patients with smallbowel involvement, capsule endoscopy is the preferred technique to visualize small bowel mucosa lesions when suspected, and deviceassisted enteroscopy is the only technique allowing for small bowel tissue sampling before surgery [41].

Radiological diagnosis of small bowel neoplasia developing in Crohn's disease is very difficult because the imaging findings are very similar to the findings of longstanding Crohn's disease and biopsy should be used to distinguish between them. The development of a mass or nodularity in a location of a luminal narrowing/obstruction should be evaluated carefully regarding the possibility of superimposed malignancy [49].

Capsule endoscopy is recommended as diagnostic modality to investigate small bowel in suspected Crohn or to assess extent and site of the disease in confirmed Crohn, if findings from such cross-sectional imaging of the small bowel are unremarkable or nondiagnostic. In the setting of small bowel neoplasia, video capsule endoscopy (VCE) plays a pivotal role for the detection of a suspected SB neoplasia. However, a retrospective study showed a suboptimal VCE sensitivity (83.3\%), with missed lesions especially in the proximal SB due to capsule rapid passage in this segment [50]. Moreover, VCE does not allow biopsies collection and does not accurately localize and grade lesions [51]. Nonetheless, in case of complete bowel exploration, VCE is a valuable tool because it allows for sensitive estimates of the location, it may be a physical mark in case of capsule retention upstream a stenosis, and with the most recent softwares the risks of reporting repeatedly a single lesion seen more times should be remarkably reduced.

In patients with suspected SB neoplasia, Device-Assisted-Enteroscopy (DAE) is rec- ommended to confirm the diagnostic suspicion, to precisely identify the cancer site, to take biopsy samples, and to mark the lesion to guide further surgical treatment [52].

Moreover, the inflammation-dysplasiaadenocarcinoma is poorly documented in Crohn's disease; dysplasia is found only in $49 \%$ of specimens of patients with small bowel adenocarcinoma [53].

Therefore, at the state of the art, there are no recommendations on endoscopic screening of small bowel cancers in $\mathrm{CD}$ patients.

\section{PATHOGENESIS}

The pathogenesis of CRC in IBD has been studied extensively in Ulcerative Colitis but in Crohn's disease is poorly defined. The development of IBD-CRC is linked to inflammation and follows a sequence of genetic alteration according to an "inflammation-dysplasia-cancer" sequence different from an "adenoma-sequence" classically described per sporadic CRC [54].

Molecular alterations and genetic abnormalities, such as chromosomal instability, microsatellite instability (MSI) and hypermethylation, seem to be similar between sporadic and IBD-associated CRC, but they occur before definite histologically defined dysplasia and in a different sequence [55].

IBD patients tend to have excessive inflammatory cell infiltration and expression of several inflammatory genes; this mucosal inflammation promotes cellular proliferation and ultimately CRC development [56].

The relationship between chronic inflammation and molecular pattern involved in carcinogenesis has been studied. Some models demonstrated the role of toll-like receptors (TLR) and tumor necrosis factor- $\alpha$ (TNF- $\alpha)$ in the activation of nuclear factor $\kappa \mathrm{B}(\mathrm{NF} \kappa \mathrm{B})$, which then induces transcription of tumorigenesis genes, including COX-2 [57]. TNF-alpha has been reported to promote inflammation and IBD-CRC by promoting deoxynucleic acid (DNA) damage, stimulating angiogenesis, and inducing expression of COX-2, which also induces angiogenesis to promote tumor growth. In murine models, TNF- $\alpha$ expression was associated with the development of colonic tumors, while TNF-R blockade reduced inflammation and tumor development [58]. 
One of the main differences between sporadic and IBD-related colonic neoplasia is that in IBD the entire colonic mucosa carries risk for neoplastic transformation that can be multifocal, as opposed to one or few premalignant adenomas or cancers in sporadic cases [59]. The cause of the field effect can be explained by the constant re-epithelialization of ulcerated and chronically inflamed colonic mucosa by abnormal healing clones that expand [60].

The pathogenesis of SBA in CD is poorly defined.Much of the current understanding of the molecular alterations involved in the development of neoplasia in IBD comes from studies of patients with ulcerative colitis (UC) who develop colorectal carcinoma, also considered to be valid in CD. SBA is usually found in inflammatory areas, which suggests that the sequence inflammation-dysplasia-cancer might be involved in the pathogenesis of SBA, but the rarity of this neoplasm makes it difficult to perform pathogenetic studies [48].

\section{CHEMOPREVENTION}

The chemopreventive effect of 5-aminosalicylic acid (5-ASA) has been widely studied, especially in UC setting; however, the results are conflicting. The European guidelines suggest that 5 -aminosalicylates (5-ASA) maintenance treatment should be continued long-term in order to induce long-term remission, that may reduce the risk of colon cancer [35]. A case-control study of the CESAME cohort shows that mesalamine therapy has a protective effect for patients with long-standing extended colitis $(\mathrm{OR}=0.5 ; 95 \% \mathrm{CI}$ : 0.2-0.9), which lacks in the remaining patients $(\mathrm{OR}=0.8$; 95\% CI: 0.3-1.7). Therefore, a chemopreventive effect of 5-ASA in patients with known risk factors for dysplasia or cancer is suggested [61].

A metanalysis by Zhao et al. shows that 5-ASA therapy was associated with a reduced risk of colorectal neoplasia in patients with ulcerative colitis, especially in case of higher daily dose (sulfasalazine $\geq 2.0$ $\mathrm{g} / \mathrm{d}$, mesalamine $\geq 1.2 \mathrm{~g} / \mathrm{d}$ ) with $\mathrm{OR}=0.51$ [0.35-0.75]. However, the chemopreventive effect of 5-aminosalicylates use in extensive ulcerative colitis was limited (OR $=1.00$; 95\% CI: 0.53-1.89) [62]. These findings were replicated in a recent metanalysis. UC patients can benefit more from 5-ASA therapy than CD patients (respec- tively $\mathrm{OR}=0.46 ; 95 \% \mathrm{CI}: 0.34-0.61$ vs. $\mathrm{OR}=0.66$; 95\% CI: 0.42-1.03). Moreover, this metanalysis shows that 5-ASA has a protective effect on $\mathrm{CRC}(\mathrm{OR}=0.54 ; 95 \%$ CI: 0.39-0.74), but not on dysplasia (OR = 0.47; 95\% CI: 0.20-1.10) [63].

An older cross-sectional study tried to assess the relationship between ursodeoxycholic acid (UDCA) use and colonic dysplasia in patients with ulcerative colitis and primary sclerosing cholangitis. UDCA use was strongly associated with decreased prevalence of colonic dysplasia $(\mathrm{OR}=0.18$; 95\% CI: 0.05-0.61) [64]. This is a special setting where the use of UDCA is specifically in sclerosing cholangitis, and when this condition is associated with ulcerative colitis, there is an increase in the risk of CRC. However, there are no adequate trials and the recent guidelines do not recommend their use as chemoprophylaxis [9].

The use of statins in CRC prophylaxis is being evaluated in recent years. Ananthakrishnan et al. showed that statin use was inversely associated with the risk of CRC in a 1376 IBD cohort. On multivariate analysis, statin use remained independently and inversely associated with $\mathrm{CRC}(\mathrm{OR}=0.42$; 95\% CI: 0.28-0.62) [65]. However, further prospective studies are needed to confirm these data.

Folic acid was also tested as a chemoprophylactic drug. A recent metanalysis by Burr et al. has collected ten studies reporting on 4517 patients. This metanalysis shows an overall protective effect for folic acid supplementation on the development of CRC, pooled hazard ratio $=0.58(95 \%$ CI: 0.37-0.80 with I = 29.7\%) [66]. Even in this case, data are not sufficient, thus further prospective studies are needed.

Although thiopurines reduce colonic inflammation and promote mucosal healing, their use is not indicated as chemoprophylaxis. A meta-analysis by Jess et al. did not find a significant protective effect of treatment with thiopurines on the risk of colorectal neoplasia in patients with IBD (OR = 0.87; 95\% CI: 0.71-1.06) [67].

Even if immunosuppressants and TNFblockers induce significant mucosal healing, and the risk of colon cancer decreased when mucosa inflammation is reduced by any means, at present there are not enough data for suggesting the use of methotrexate or TNF-blockers as chemopreventive agents against CRC, at least according to current guidelines [9]. 


\section{CONCLUSIONS}

The individual patient CRC risk should include personal and disease-related factors. Newer endoscopic techniques allow for more effective surveillance strategies, if compared with white-light standard definition endoscopy. Chemical chromoendoscopy or high-definition virtual or chemical chromoendoscopy with targeted and/or random biopsies is the standard-of-care for IBD patients. They should be performed as much as possible in case of endoscopic remission. Endoscopic resection techniques may be appropriate if complete resection is possible, even if proctocolectomy should always be carefully considered as a radical therapeutic option to stop progression from dysplasia to CRC. Peculiar fields for CRC surveillance programs are ileal pouch anal anastomosis surveillance and surveillance of anal and perianal Crohn's disease for anal adenocarcinoma.

\section{Keypoints}

- Risks of colorectal cancer (CRC) are increased among inflammatory bowel disease (IBD) patients. Still the risk class should be best classified according to independent CRC risks factors, including IBD colonic involvement extent and activity, CRC familial history, previous dysplasia

- Based on low/medium/high risks of IBD-related CRC, patients may be allocated to different frequency of surveillance (surveillance every 5 years in low risk, every 3 years in intermediate risk, and yearly in high-risk patients)

- High-definition endoscopy, associated with dye-spray (chemical) or virtual (electronical) chromoendoscopy, together with targeted biopsies, are the standard-of-care technique for surveillance

- Visible dysplastic lesions (outside or within colitis area) should be resected endoscopically with standard polypectomy, endoscopical mucosal resection, or endoscopical submucosal resection

- When invisible dysplastic lesions are identified at a surveillance endoscopy, the risks of progression to cancer and of being unable to replicate surveillance of the same area lead to a preference for proctocolectomy

- Proctocolectomy should always be considered a safe and long-lasting effective therapeutic option

- In patients undergone proctocolectomy plus ileal pouch anal anastomosis, dysplasia of the rectal cuff should be surveilled, especially if dysplasia was the indication to surgery

- In patients with chronic long-lasting perianal Crohn's disease, anal or fistula-related adenocarcinoma should be suspected, especially if disease change its phenotype

\section{Funding}

This article writing was supported by Fondazione IBD Onlus.

Conflicts of interests

The authors declare they have no competing financial interests concerning the topics of this article.

\section{REFERENCE}

1. Jess T, Rungoe C, Peyrin-Biroulet L. Risk of Colorectal Cancer in Patients With Ulcerative Colitis: A Meta-analysis of Population-Based Cohort Studies. Clin Gastroenterol Hepatol2012; 10: 639-45; https://doi.org/10.1016/j.cgh.2012.01.010

2. Jess T, Gamborg M, Matzen P, et al. Increased Risk of Intestinal Cancer in Crohn's Disease: A Meta-Analysis of Population-Based Cohort Studies. Am J Gastroenterology 2005; 100: 2724-9; https://doi.org/10.1111/j.1572-0241.2005.00287.x

3. Olén O, Erichsen R, Sachs MC, et al. Colorectal cancer in Crohn's disease: a Scandinavian population-based cohort study. Lancet Gastroenterol Hepatol 2020; 5: 475-84; https://doi. org/10.1016/S2468-1253(20)30005-4 
4. Jess T, Frisch M, Simonsen J. Trends in Overall and Cause-Specific Mortality Among Patients With Inflammatory Bowel Disease From 1982 to 2010. Clin Gastroenterol Hepatol 2013; 11: 43-48; https://doi.org/10.1016/j.cgh.2012.09.026

5. Jess T, Simonsen J, Jørgensen KT, et al. Decreasing Risk of Colorectal Cancer in Patients With Inflammatory Bowel Disease Over 30 Years. Gastroenterology 2012; 143: 375-81.e1; https:// doi.org/10.1053/j.gastro.2012.04.016

6. Gillen CD, Walmsley RS, Prior P, et al. Ulcerative colitis and Crohn's disease: a comparison of the colorectal cancer risk in extensive colitis. Gut 1994; 35: 1590-92; https://doi.org/10.1136/ gut.35.11.1590

7. Eaden JA. The risk of colorectal cancer in ulcerative colitis: a meta-analysis. Gut 2001; 48: 52635; https://doi.org/10.1136/gut.48.4.526

8. Annese V, Daperno M, Rutter MD, et al. European evidence based consensus for endoscopy in inflammatory bowel disease. J Crohns Colitis 2013; 7: 982-1018; https://doi.org/10.1016/j. crohns.2013.09.016

9. Magro F, Gionchetti P, Eliakim R, et al. Third European Evidence-based Consensus on Diagnosis and Management of Ulcerative Colitis. Part 1: Definitions, Diagnosis, Extra-intestinal Manifestations, Pregnancy, Cancer Surveillance, Surgery, and Ileo-anal Pouch Disorders. J Crohns Colitis 2017; 11: 649-70; https://doi.org/10.1093/ecco-jcc/jjx008

10. Askling J, Dickman PW, Ekbom A, et al. Family history as a risk factor for colorectal cancer in inflammatory bowel disease. Gastroenterology 2001; 120: 1356-62; https://doi.org/10.1053/ gast.2001.24052

11. Zheng H-H,Jiang X-L. Increased risk of colorectal neoplasia in patients with primary sclerosing cholangitis and inflammatory bowel disease: a meta-analysis of 16 observational studies. Eur J Gastroenterol Hepatol 2016; 28: 383-90; https://doi.org/10.1097/MEG.0000000000000576

12. Schlemper RJ. The Vienna classification of gastrointestinal epithelial neoplasia. Gut 2000; 47: 251-5; https://doi.org/10.1136/gut.47.2.251

13. Kamiński M, Hassan C, Bisschops R, et al. Advanced imaging for detection and differentiation of colorectal neoplasia: European Society of Gastrointestinal Endoscopy (ESGE) Guideline. Endoscopy 2014; 46: 435-57; https://doi.org/10.1055/s-0034-1365348

14. Laine L, Kaltenbach T, Barkun A, et al. SCENIC international consensus statement on surveillance and management of dysplasia in inflammatory bowel disease. Gastrointest Endosc 2015; 81: 489-501.e26; https://doi.org/10.1016/j.gie.2014.12.009

15. Subramanian V, Ragunath K. Advanced Endoscopic Imaging: A Review of Commercially Available Technologies. Clin Gastroenterol Hepatol 2014; 12: 368-76.e1; https://doi. org/10.1016/j.cgh.2013.06.015

16. Subramanian V, Ramappa V, Telakis E, et al. Comparison of High Definition with Standard White Light Endoscopy for Detection of Dysplastic Lesions During Surveillance Colonoscopy in Patients with Colonic Inflammatory Bowel Disease. Inflamm Bowel Dis 2013; 19: 350-5; https://doi.org/10.1002/ibd.23002

17. van den Broek FJC, Stokkers PCF, Reitsma JB, et al. Random Biopsies Taken During Colonoscopic Surveillance of Patients With Longstanding Ulcerative Colitis: Low Yield and Absence of Clinical Consequences. Am J Gastroenterol 2014; 109: 715-22; https://doi. org/10.1038/ajg.2011.93

18. East JE, Saunders BP, Burling D, et al. Surface Visualization at CT Colonography Simulated Colonoscopy: Effect of Varying Field of View and Retrograde View. Am J Gastroenterology 2007; 102: 2529-35; https://doi.org/10.1111/j.1572-0241.2007.01429.x

19. Shergill AK, Lightdale JR, Bruining DH, et al. The role of endoscopy in inflammatory bowel disease. Gastrointest Endosc 2015; 81: 1101-21.e13; https://doi.org/10.1016/j.gie.2014.10.030

20. Iacucci M, Panaccione R, Ghosh S. Advances in Novel Diagnostic Endoscopic Imaging Techniques in Inflammatory Bowel Disease. Inflamm Bowel Dis 2013; 19: 873-80; https://doi. org/10.1097/MIB.0b013e318280143f

21. Subramanian V, Mannath J, Ragunath K, et al. Meta-analysis: the diagnostic yield of chromoendoscopy for detecting dysplasia in patients with colonic inflammatory bowel disease: Meta-analysis: chromoendoscopy for IBD surveillance. Aliment Pharmacol Ther 2011; 33: 30412; https://doi.org/10.1111/j.1365-2036.2010.04525.x

22. Marion JF, Waye JD, Israel Y, et al. Chromoendoscopy Is More Effective Than Standard Colonoscopy in Detecting Dysplasia During Long-term Surveillance of Patients With Colitis. Clin Gastroenterol Hepatol 2016; 14: 713-9; https://doi.org/10.1016/j.cgh.2015.11.011

23. Iannone A, Ruospo M, Palmer SC, et al. Systematic review with network meta-analysis: endoscopic techniques for dysplasia surveillance in inflammatory bowel disease. Aliment Pharmacol Ther 2019; 50: 858-71; https://doi.org/10.1111/apt.15493 
24. Konijeti GG, Shrime MG, Ananthakrishnan AN, et al. Cost-effectiveness analysis of chromoendoscopy for colorectal cancer surveillance in patients with ulcerative colitis. Gastrointest Endosc 2014; 79: 455-65; https://doi.org/10.1016/j.gie.2013.10.026

25. Moussata D, Allez M, Cazals-Hatem D, et al. Are random biopsies still useful for the detection of neoplasia in patients with IBD undergoing surveillance colonoscopy with chromoendoscopy? Gut 2018; 67: 616-24; https://doi.org/10.1136/gutjnl-2016-311892

26. Iacucci M, Kaplan GG, Panaccione R, et al. A Randomized Trial Comparing High Definition Colonoscopy Alone With High Definition Dye Spraying and Electronic Virtual Chromoendoscopy for Detection of Colonic Neoplastic Lesions During IBD Surveillance Colonoscopy. Am J Gastroenterol 2018; 113: 225-34; https://doi.org/10.1038/ajg.2017.417

27. Bisschops R, Bessissow T, Joseph JA, et al. Chromoendoscopy versus narrow band imaging in UC: a prospective randomised controlled trial. Gut 2018; 67: 1087-94; https://doi.org/10.1136/ gutjnl-2016-313213

28. Shen B, Kochhar G, Navaneethan U, et al. Role of interventional inflammatory bowel disease in the era of biologic therapy: a position statement from the Global Interventional IBD Group. Gastrointest Endosc 2019; 89: 215-37; https://doi.org/10.1016/j.gie.2018.09.045

29. Soetikno R, Subramanian V, Kaltenbach T, et al. The Detection of Nonpolypoid (Flat and Depressed) Colorectal Neoplasms in Patients With Inflammatory Bowel Disease. Gastroenterology 2013; 144: 1349-52.e6; https://doi.org/10.1053/j.gastro.2013.04.008

30. Gulati S, Emmanuel A, Burt M, et al. Outcomes of Endoscopic Resections of Large Laterally Spreading Colorectal Lesions in Inflammatory Bowel Disease: a Single United Kingdom Center Experience. Inflamm Bowel Dis 2018; 24:1196-203; https://doi.org/10.1093/ibd/izx113

31. Kinoshita S, Uraoka T, Nishizawa T, et al. The role of colorectal endoscopic submucosal dissection in patients with ulcerative colitis. Gastrointest Endosc 2018; 87: 1079-84; https:// doi.org/10.1016/j.gie.2017.10.035

32. Kochhar G, Steele S, Sanaka M, et al. Endoscopic Submucosal Dissection for Flat Colonic Polyps in Patients With Inflammatory Bowel Disease, A Single-Center Experience. Inflamm Bowel Dis 2018; 24: e14-e15; https://doi.org/10.1093/ibd/izy101

33. Odze RD, Farraye FA, Hecht JL, et al. Long-term follow-up after polypectomy treatment for adenoma-like dysplastic lesions in ulcerative colitis. Clin Gastroenterol Hepatol 2004; 2: 534-41; https://doi.org/10.1016/S1542-3565(04)00237-X

34. Thomas T, Abrams KA, Robinson RJ, et al. Meta-analysis: cancer risk of low-grade dysplasia in chronic ulcerative colitis. Aliment Pharmacol Ther 2007; 25: 657-68; https://doi.org/10.1111/ j.1365-2036.2007.03241.x

35. Feakins RM. Inflammatory bowel disease biopsies: updated British Society of Gastroenterology reporting guidelines. J Clin Pathol 2013; 66: 1005-26; https://doi.org/10.1136/ jclinpath-2013-201885

36. Navaneethan U, Jegadeesan R, Gutierrez NG, et al. Progression of low-grade dysplasia to advanced neoplasia based on the location and morphology of dysplasia in ulcerative colitis patients with extensive colitis under colonoscopic surveillance. J Crohns Colitis 2013; 7: e684-e691; https://doi.org/10.1016/j.crohns.2013.06.006

37. Derikx LAAP, Kievit W, Drenth JPH, et al. Prior Colorectal Neoplasia Is Associated With Increased Risk of Ileoanal Pouch Neoplasia in Patients With Inflammatory Bowel Disease. Gastroenterology 2014; 146: 119-28.e1; https://doi.org/10.1053/j.gastro.2013.09.047

38. Khan F, Shen B. Inflammation and Neoplasia of the Pouch in Inflammatory Bowel Disease. Curr Gastroenterol Rep 2019; 21: 10; https://doi.org/10.1007/s11894-019-0679-4

39. Broomé U, Bergquist A. Primary Sclerosing Cholangitis, Inflammatory Bowel Disease, and Colon Cancer. Semin Liver Dis 2006; 26: 031-041; https://doi.org/10.1055/s-2006-933561

40. Navaneethan U, Kochhar G, Venkatesh PGK, et al. Duration and severity of primary sclerosing cholangitis is not associated with risk of neoplastic changes in the colon in patients with ulcerative colitis. Gastrointest Endosc 2012; 75: 1045-54.e1; https://doi.org/10.1016/j.gie.2012.01.015

41. Rao BB, Lashner B, Kowdley KV. Reviewing the Risk of Colorectal Cancer in Inflammatory Bowel Disease After Liver Transplantation for Primary Sclerosing Cholangitis. Inflamm Bowel Dis 2018; 24: 269-76; https://doi.org/10.1093/ibd/izx056

42. Beaugerie L, Carrat F, Nahon S, et al. High Risk of Anal and Rectal Cancer in Patients With Anal and/or Perianal Crohn's Disease. Clin Gastroenterol Hepatol 2018; 16: 892-9.e2; https:// doi.org/10.1016/j.cgh.2017.11.041

43. Annese V, Beaugerie L, Egan L, et al. European Evidence-based Consensus: Inflammatory Bowel Disease and Malignancies.J Crohns Colitis 2015; 9: 945-65; https://doi.org/10.1093/ ecco-jcc/jjv141 
44. Laukoetter MG, Mennigen R, Hannig CM, et al. Intestinal Cancer Risk in Crohn's Disease: A Meta-Analysis. J Gastrointest Surg 2011; 15: 576-83; https://doi.org/10.1007/s11605-010$1402-9$

45. Elriz K, Carrat F, Carbonnel F, et al. Incidence, Presentation, and Prognosis of Small Bowel Adenocarcinoma in Patients with Small Bowel Crohn's Disease: A Prospective Observational Study. Inflamm Bowel Dis 2013: 1; https://doi.org/10.1097/MIB.0b013e31828c84f2

46. Biancone L, Armuzzi A, Scribano ML, et al. Cancer Risk in Inflammatory Bowel Disease: A 6-Year Prospective Multicenter Nested Case-Control IG-IBD Study. Inflamm Bowel Dis 2019: izz155; https://doi.org/10.1093/ibd/izz155

47. Giuffrida P, Vanoli A, Arpa G, et al. Small Bowel Carcinomas Associated with ImmuneMediated Intestinal Disorders: the Current Knowledge. Cancers (Basel) 2018; 11:31; https:// doi.org/10.3390/cancers11010031.

48. Egan L, D'Inca R, Jess T, et al. Non-colorectal intestinal tract carcinomas in inflammatory bowel disease: Results of the 3rd ECCO Pathogenesis Scientific Workshop (II). J Crohns Colitis 2014; 8: 19-30; https://doi.org/10.1016/j.crohns.2013.04.009

49. Weber NK, Fletcher JG, Fidler JL, et al. Clinical characteristics and imaging features of small bowel adenocarcinomas in Crohn's disease. Abdom Imaging 2015; 40: 1060-7; https://doi. org/10.1007/s00261-014-0144-7

50. Zagorowicz ES. Small bowel tumors detected and missed during capsule endoscopy: Single center experience. WJG 2013; 19: 9043; https://doi.org/10.3748/wjg.v19.i47.9043

51. Bourreille A, Ignjatovic A, Aabakken L, et al. Role of small-bowel endoscopy in the management of patients with inflammatory bowel disease: an international OMED-ECCO consensus. Endoscopy 2009; 41: 618-37; https://doi.org/10.1055/s-0029-1214790

52. Pennazio M, Spada C, Eliakim R, et al. Small-bowel capsule endoscopy and device-assisted enteroscopy for diagnosis and treatment of small-bowel disorders: European Society of Gastrointestinal Endoscopy (ESGE) Clinical Guideline. Endoscopy 2015; 47: 352-86; https:// doi.org/10.1055/s-0034-1391855

53. Svrcek M, Piton G, Cosnes J, et al. Small Bowel Adenocarcinomas Complicating Crohn's Disease Are Associated With Dysplasia: A Pathological and Molecular Study. Inflamm Bowel Dis 2014; 20: 1584-92; https://doi.org/10.1097/MIB.0000000000000112

54. Feagins LA, Souza RF, Spechler SJ. Carcinogenesis in IBD: potential targets for the prevention of colorectal cancer. Nat Rev Gastroenterol Hepatol 2009; 6: 297-305; https://doi.org/10.1038/ nrgastro.2009.44

55. Markowitz SD, Bertagnolli MM. Molecular Basis of Colorectal Cancer. N Engl J Med 2009; 361: 2449-60; https://doi.org/10.1056/NEJMra0804588

56. Velayos FS, Loftus EV,Jess T, et al. Predictive and Protective Factors Associated With Colorectal Cancer in Ulcerative Colitis: A Case-Control Study. Gastroenterology 2006; 130: 1941-9; https:// doi.org/10.1053/j.gastro.2006.03.028

57. Goel GA, Kandiel A, Achkar JP, et al. Molecular Pathways Underlying IBD-Associated Colorectal Neoplasia: Therapeutic Implications. Am J Gastroenterol 2011; 106: 719-30; https:// doi.org/10.1038/ajg.2011.51

58. Poutahidis T, Haigis KM, Rao VP, et al. Rapid reversal of interleukin-6-dependent epithelial invasion in a mouse model of microbially induced colon carcinoma. Carcinogenesis 2007; 28: 2614-23; https://doi.org/10.1093/carcin/bgm180

59. Ullman TA, Itzkowitz SH. Intestinal Inflammation and Cancer. Gastroenterology 2011; 140: 1807-16.e1; https://doi.org/10.1053/j.gastro.2011.01.057

60. Lyda M, Noffsinger A, Belli J, et al. Microsatellite instability and K- mutations in patients with ulcerative colitis. Hum Pathol 2000; 31: 665-71; https://doi.org/10.1053/hupa.2000.7643

61. Beaugerie L, Kirchgesner J. Balancing Benefit vs Risk of Immunosuppressive Therapy for Individual Patients With Inflammatory Bowel Diseases. Clin Gastroenterol Hepatol 2019; 17: 370-9; https://doi.org/10.1016/j.cgh.2018.07.013

62. Zhao L-N, Li J-Y, Yu T, et al. 5-Aminosalicylates Reduce the Risk of Colorectal Neoplasia in Patients with Ulcerative Colitis: An Updated Meta-Analysis. Cominelli F, ed. PLoS ONE 2014; 9: e94208; https://doi.org/10.1371/journal.pone.0094208

63. Qiu X, Ma J, Wang K, et al. Chemopreventive effects of 5-aminosalicylic acid on inflammatory bowel disease-associated colorectal cancer and dysplasia: a systematic review with meta-analysis. Oncotarget 2017; 8: 1031-45; https://doi.org/10.18632/oncotarget.13715

64. Tung BY, Emond MJ, Haggitt RC, et al. Ursodiol Use Is Associated with Lower Prevalence of Colonic Neoplasia in Patients with Ulcerative Colitis and Primary Sclerosing Cholangitis. Ann Intern Med 2001; 134: 89; https://doi.org/10.7326/0003-4819-134-2-200101160-00008 
65. Ananthakrishnan AN, Cagan A, Cai T, et al. Statin Use Is Associated With Reduced Risk of Colorectal Cancer in Patients With Inflammatory Bowel Diseases. Clin Gastroenterol Hepatol 2016; 14: 973-9; https://doi.org/10.1016/j.cgh.2016.02.017

66. Burr NE, Hull MA, Subramanian V.Folic Acid Supplementation May Reduce Colorectal Cancer Risk in Patients With Inflammatory Bowel Disease: A Systematic Review and Meta-Analysis. J Clin Gastroenterol 2017; 51: 247-53; https://doi.org/10.1097/MCG.0000000000000498

67. Jess T, Lopez A, Andersson M, et al. Thiopurines and Risk of Colorectal Neoplasia in Patients With Inflammatory Bowel Disease: A Meta-analysis. Clin Gastroenterol Hepatol 2014; 12: 1793-1800.e1; https://doi.org/10.1016/j.cgh.2014.05.019 